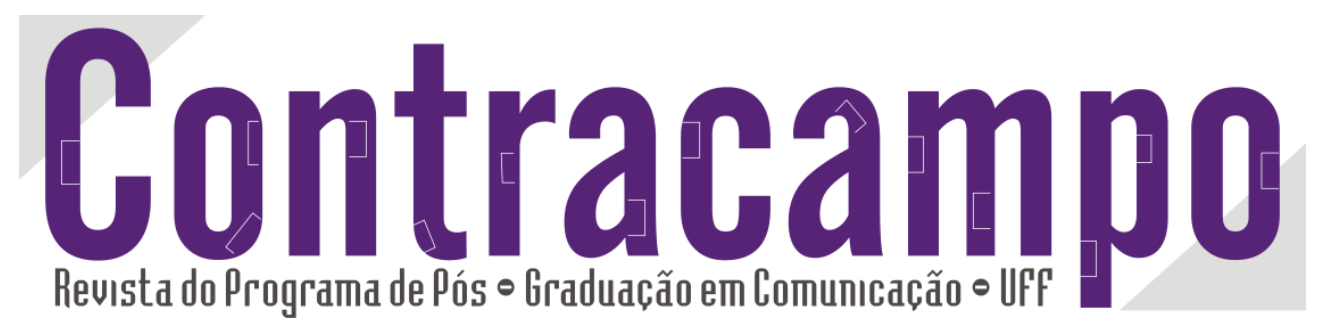

\title{
Estudos de jornalismo e ambiente: panorama comparativo Brasil-Portugal
}

\author{
Journalism and environment studies: \\ a comparative panorama Brazil-Portugal
}

\begin{abstract}
Antônio Teixeira de Barros
antonibarros@gmail.com

Jornalista, mestre em Comunicação e doutor em Sociologia.

Docente e pesquisador do Programa de Pós-Graduação do Centro de Formação Política da Câmara dos Deputados.
\end{abstract}

Ao citar este artigo, utilize a seguinte referência bibliográfica

BARROS, AnT6onio Teixeira de. O interlocutor jornalístico: representações imaginárias do leitor do Estadão. In: Revista Contracampo, v. 24, n. 1, ed. julho, ano 2012. Niterói: Contracampo, 2012. Pags: 140-158.

Enviado em: 31 de jan. de 2012 Aceito em: 04 de mai. De 2012

\section{PPG COM $=$ UFF}

\section{Edição 24/2012}

Temáticas diversas

Contracampo

Niterói (RJ), v. 24, n. 1, jul./2012.

e-ISSN 2238-2577 www.uff.br/contracampo

A Revista Contracampo é uma revista eletrônica do Programa de PósGraduação em Comunicação da Universidade Federal Fluminense e tem como objetivo contribuir para a reflexão crítica em torno do campo midiático, atuando como espaço de circulação da pesquisa e do pensamento acadêmico. 


\section{Resumo}

Panorama comparativo dos estudos sobre jornalismo e ambiente realizados no Brasil e em Portugal, após a Rio 92. O objetivo é identificar paralelos nas vertentes teóricas e nas questões profissionais. Pesquisa realizada com base na técnica de metanálise, ou seja, revisão sistemática de dez estudos de cada país. No campo teórico, destacam-se estudos sobre agendamento e tematização (agendasetting), seleção de informações (gatekeeping), e produção jornalística (newsmaking). Nas práticas a ênfase está na complexidade técnica, formação específica e nas características dos relatos jornalísticos sobre o tema. Conclui que o processo que levou o ambiente a se estabelecer na agenda da mídia nos dois países resulta da conjunção de fatores políticos e culturais, da atuação de instituições científicas, partidos políticos, movimentos socioambientais e empresariais.

Palavras-chave: estudos de jornalismo; jornalismo ambiental; Brasil e Portugal.

\section{Abstract}

It describes a comparative panorama about journalism and environment in Brazil and Portugal, after the Rio 92 Conference. The aim is to identify simillarities on theoretical approaches as well as on professional matters. It envolves a research based on the metanalysis, that is to say, a sistematic research of 10 studies of each country. On the theorethical field, we can stress studies on agenda-setting, gatekeeping and newsmaking. On the practical field, the enphasys is on the technical complexity, on the specific training and on the characteristics of journalist's reports about the theme. It concludes that the processes which led the environment to set itself on the mediatic agenda of both coutries comes from the conjuction of political and cultural factors, as well as from the performance of scientific institutions, political parties, socioenvironmental and enterpreneurials movements.

Keywords: journalism studies; environmental journalism; Brazil and Portugal. 
$\mathrm{H}$ istoricamente, o jornalismo exerceu papel expressivo na divulgação ambiental, um fenômeno que adquiriu projeção internacional. Inicialmente, a ecologia era tratada de forma episódica e fragmentada, mas com o passar do tempo, tornou-se um super tema, ao romper a lógica de assunto eventual da agenda midiática para tornar-se problemática com abordagem continuada e recorrente, com ênfase para os aspectos socioambientais. Atualmente, o noticiário abrange assuntos diretamente relacionados ao cotidiano do cidadão, como coleta seletiva de lixo, desperdício de água, redução do consumo de energia elétrica nos domicílios, uso de combustíveis fósseis nos automóveis etc. Contudo, essa abordagem é recente, o que justifica a necessidade de se analisar, de forma comparativa, como se deu a evolução e as redefinições dessa no Brasil e em Portugal. Este, portanto, é o eixo analítico deste paper, cujo objetivo principal é identificar as vertentes teóricas que orientam as pesquisas e as abordagens relacionadas às práticas profissionais, além de apontar correlações e paralelos entre os estudos realizados nos dois países.

O pressuposto que norteia o estudo é o de que o discurso da imprensa sobre ambiente não deve ser entendido como produção autônoma, uma vez que rotineiramente as notícias se reportam às concepções de diversos atores sociais (instituições estatais, partidos políticos, entidades científicas, movimentos sociais, ambientalistas e o setor empresarial). Além da diversidade de atores, a imprensa passou a destacar diferentes aspectos relacionados aos temas ambientais (naturais, políticos, econômicos, culturais, ideológicos). Trata-se de um discurso condicionado por múltiplos fatores, segundo a perspectiva da teoria multifatorial da notícia (Sousa, 2000; 2006). Grande parte das reportagens sobre ambiente tem como referente as ações do Estado, da comunidade científica e das organizações ambientalistas. O jornalismo, como discurso social poroso e permeável, recebe influências de todas as vertentes do discurso ecológico-ambiental, portanto.

Diante do exposto, cabe apresentar o problema de pesquisa, o qual parte das seguintes questões: (1) Existem diferenças expressivas nos paradigmas jornalísticos que norteiam as investigações nos países mencionados? (2) Do ponto de vista teórico, como os pesquisadores caracterizam a agenda ambiental (agendamento), os critérios de noticiabilidade e os valores-notícias nas pesquisas acadêmicas sobre jornalismo ambiental? (3) Quais as teorias predominantes na fundamentação teórica dos estudos de 
jornalismos nos dois países? (4) Quais as questões práticas mais relevantes e como elas são abordadas?

\section{Descrição da pesquisa}

Além da pesquisa bibliográfica, a metodologia utilizada compreende a técnica denominada metanálise, ou seja, revisão de literatura de forma sistemática, a fim de identificar os paralelos entre os estudos elaborados nos dois países sobre a relação entre jornalismo e ambiente. Esse recurso consiste no exame minucioso de investigações já realizadas sobre um tema determinado, a fim de organizar o conhecimento produzido, comparar tendências, metodologias e produzir inferências (Clarke, 2001). Nessa perspectiva, a metanálise foi aplicada com base na concepção operacional de obrassíntese, ou seja, publicações expressivas e representativas em termos de abordagens, abrangência temática, ferramentas metodológicas e referencial teórico utilizado. ${ }^{1}$ Foram selecionadas dez obras (cinco de cada país) ${ }^{2}$ referentes ao período estudado. Em suma, o estudo apresenta abordagem qualitativa, embora a técnica da metanálise também utilize procedimentos quantitativos (que não foram empregados no estudo em tela). O corpus foi definido de modo a contemplar os textos emblemáticos dos estudos sobre jornalismo e ambiente no Brasil e em Portugal (obras-síntese), a fim de permitir a identificação do perfil dominante das pesquisas nos dois países em questão.

A seleção das obras-síntese se deu com base em critérios delineados por pesquisa prévia, com levantamento da produção de cada país, por década, mediante registro em relatórios bibliográficos. Considerou-se ainda a abrangência do estudo, as

\footnotetext{
${ }^{1}$ Foram selecionadas dez obras (cinco de cada país), de modo a incluir no corpus da pesquisa obrassíntese referentes às diversas fases do período histórico estudado. No âmbito deste trabalho, entende por obra-síntese uma investigação que reúne um capital de conhecimentos que sintetiza as principais idéias, paradigmas e procedimentos metodológicos referentes a uma área de conhecimento em um determinado período histórico. Assim, uma investigação pode ser representativa sem necessariamente incluir todos os estudos realizados em uma década, por exemplo, visto que os conteúdos se repetem. O pressuposto, portanto, é que uma única obra-síntese pode servir de referência para a análise e compreensão dos conteúdos de uma área de conhecimentos no decorrer de um período específico, como um decênio ou um qüinqüênio.

${ }^{2} \mathrm{O}$ corpus original da pesquisa é composto pelos seguintes estudos: Brasil: (1) DENCKER, A. F. \& KUNSCH, M. M. K. (1996); (2) OLIVEIRA, M.T.C. (1991); (3) COSTA, L. M. (2006); (4) MOTTA, L. G. et al. (2006); (5) TRIGUEIRO, A. (2005). Portugal: (6) SCHMIDT, L. (2003); (7) GARCIA, R (2004); (8) PEREIRA ROSA, G. (2006); (9) VIEIRA, P. A. (2006); (10) FREITAS, H. de S. (2007). Cabe ressaltar, contudo, que o reduzido espaço deste artigo não permite a exploração ampla e detalhada de todas as obras mencionadas. Para ter acesso à análise completa ver: BARROS e SOUSA, 2010.
} 
teorias de base, o escopo da análise empírica e a consistência teórico-analítica. Observou-se também o reconhecimento e legitimidade desses estudos pela comunidade acadêmica no Brasil e em Portugal, a partir do levantamento de citações em textos apresentados em congressos científicos, artigos de periódicos, capítulos de livros e similares.

Cabe ressaltar que a análise não se limitou às obras selecionadas. De forma complementar foram utilizadas dezenas de outras publicações, a fim de complementar as informações. O material complementar é composto por textos de periódicos, de portais acadêmicos, comunicações científicas, livros e capítulos de livros relacionados ao tema. Em alguns casos foram referenciados estudos nos quais o tema jornalismo de ambiente não aparecia em primeiro plano, mas a leitura revelava dados e informações de interesse para a contextualização ou para a complementação de explicações expostas nas obras que compunham o corpus.

\section{O jornalismo e a diversificação dos atores ambientais após a Rio 92}

A Rio 92 contribuiu para ampliar a participação da sociedade civil em todo o mundo - o que também ocorreu no Brasil - com a emergência de novos atores sociais do ambiente, em um contexto sócio-histórico de distintas bases produtivas e de diferentes eixos de transformações sociais. É neste quadro de mudanças no cenário internacional, que o ambientalismo se constitui como força política "tanto no que diz respeito à constituição de um corpo específico de valores, como a definição e agregação de atores com ele envolvidos" (Figueiredo,1996, p.120). A diversificação dos atores sociais está diretamente relacionada com a complexificação do ambientalismo, numa perspectiva agregadora, apesar das incompatibilidades existentes, das disputas de interesses e por visibilidade. A problemática ambiental também compreende uma alta diversidade de agentes sociais, na medida em que mobiliza a sociedade civil, as organizações não-governamentais, o mercado, o Estado e o sistema político internacional (Barros (1996, p.124).

Essa rearticulação das forças ambientais trouxe vantagens, em função da ampliação dos agentes envolvidos, da visibilidade e do aumento da consciência ambiental, entre outros fatores. Entretanto, esse cenário político polinucleado, com a 
predominância das retóricas conciliadoras, em prol do desenvolvimento sustentável, numa perspectiva de harmonização da ecologia com a economia, também trouxe desvantagens, especialmente com o enfraquecimento dos movimentos ambientalistas de natureza mais radical. A institucionalização dessa perspectiva, segundo a análise da autora supracitada, reprimiu as correntes mais revolucionárias, a exemplo das vertentes ancoradas no ecossocialismo ou ambientalismo libertário e radical. Por outro lado, a perda do idealismo dos movimentos de inspiração radical pode ter sido compensado com o pragmatismo das organizações não-governamentais do ambiente mais empenhadas em alianças em prol do desenvolvimento sustentável do que no confronto ideológico com o Estado e o os setores empresariais (Barros, 1996).

Pensadores como Norberto Bobbio (1992) e Eric Hobsbawn (1995) chamam atenção para a relação do ambientalismo com uma rede de outros atores sociais. Para o primeiro autor, os movimentos em defesa da natureza não devem ser compreendidos como iniciativas isoladas e autônomas, mas como parte de um conjunto de movimentos em defesa dos direitos humanos, incluindo as liberdades individuais, os direitos políticos e sociais. O ambientalismo, na visão de Bobbio se insere no âmbito dos chamados direitos de terceira geração (direitos étnicos, de gênero, de imigrantes, qualidade de vida, ecológicos etc.) ou seja, o direito relativo à natureza, no qual os sujeitos não são entendidos como indivíduos, grupos sociais, categorias profissionais ou instituições sociais. Em sua avaliação, nesses direitos de terceira geração, o sujeito é a própria humanidade. Hobsbawn complementa que esses movimentos apontam para reivindicações que exigem mudanças em toda a estrutura da sociedade e apelam para a adesão generalizada das pessoas e não apenas de categorias específicas. Os direitos ambientais são associados às reivindicações, campanhas e manifestações públicas em prol da paz, da qualidade de vida, da diversidade cultural, da integração sociocultural, do bem-estar geral da humanidade, independentemente de sua raça, religião, gênero ou nacionalidade.

Conforme Scherer-Warren (1996), é esse aspecto de capilaridade e amplitude do ambientalismo que impulsionou a formação de redes inter, trans e multinacionais, com a contribuição de mais um elemento que catalisou a lógica das redes, que foi a ampliação das possibilidades da comunicação eletrônica, especialmente com a internet. Nesse contexto, a autora destaca um conjunto de estratégias dos atores sociais que incluem o 
ambientalismo em seu campo de ação: (a) parcerias entre o poder público e organizações privadas; (b) pressões institucionais; (c) intervenção na opinião pública; (d) estímulo à vigília cidadã.

$\mathrm{Na}$ prática, todas essas estratégias se combinam. A primeira tem como meta a adesão de representantes de instituições governamentais com poder de decisão e intervenção nas políticas públicas, como conselhos municipais e prefeituras. A segunda é voltada para a alteração ou proposição de normas, leis, acordos internacionais e agendamento de debates, conferências e fóruns deliberativos sobre o assunto. A terceira prioriza a realização de protestos, campanhas, manifestos e eventos diversificados, com o intuito de ampliar a visibilidade aos temas ambientais, segundo o enquadramento das organizações ambientalistas. A última tenta prolongar o resultado das anteriores, com a instrumentalização da ação política organizada por grupos menores, a fim de cobrar a aplicação e a efetividade de medidas políticas, legislativas ou de ações governamentais. Os movimentos ambientalistas tentam transformar os cidadãos em "fiscais do ambientalismo".

\section{Mapeamento dos eixos teóricos dos estudos analisados}

Aspectos gerais

Os estudos analisados apresentam em comum o referencial teórico focado nas vertentes mais recentes das teorias da comunicação e do jornalismo, chanceladas pela "sociologia dos emissores", área que estuda a formação da agenda pública (agendasetting e tematização), a seleção de informações (gatekeeping) e o processo de produção da informação jornalística (newsmaking), além da teoria multifatorial da notícia. ${ }^{3}$

Apesar das referências teóricas comuns, do ponto de vista específico da análise sobre a relação entre mídia e ambiente, não há indício de intercâmbio acadêmico entre os estudiosos dos dois países. As referências teóricas e metodológicas principais que norteiam as análises são praticamente as mesmas, ${ }^{4}$ nos dois países, mas nenhum estudo

\footnotetext{
${ }^{3}$ Em termos mais amplos, predominam três vertentes teóricas que se complementam: (a) ciências sociais; (b) sociologia do ambiente; (c) teorias da comunicação e do jornalismo. Contudo, devido à falta de espaço, neste paper, são enfatizados apenas os aspectos mais específicos das teorias do jornalismo.

${ }^{4}$ Entre as referências principais destacam-se: (1) do ponto de vista metodológico: Laurence Bardin, Jorge Pedro Sousa, especialmente no que se refere às técnicas de análise de conteúdo. (2) Acerca das teorias da comunicação e do jornalismo, os autores mais relevantes são Mauro Wolf, Nelson Traquina, Jorge Pedro Sousa, Warren Breed, Johan Galtung, Mari Ruge e Gaye Tuchman. (3) Quanto às referências de autores
} 
específico sobre jornalismo ambiental realizado no Brasil faz referência a pesquisas/pesquisadores portugueses e vice-versa.

Do ponto de vista bibliográfico, em geral, os trabalhos dos autores portugueses apresentam vasta revisão de literatura sobre os modelos teóricos, enquanto os brasileiros tendem a explorar a relação específica entre o referencial teórico adotado e as questões analisadas, sem o objetivo de apresentar amplo inventário bibliográfico. Assim, os textos portugueses são mais abrangentes, enquanto os brasileiros são mais focados na relação entre o objeto empírico e os pressupostos teóricos específicos referentes ao problema investigado.

Pereira Rosa (2006) faz uma síntese dos estudos jornalísticos realizados em Portugal, baseados nos modelos interacionistas, construtivistas, no agendamento, na tematização, nas rotinas produtivas e no papel das fontes jornalísticas. ${ }^{5}$ Ao se basear nos pressupostos teóricos oriundos do campo da sociologia do jornalismo, o autor enfatiza as análises que reforçam o papel dos jornalistas na produção informativa, da influência das organizações noticiosas sobre o trabalho jornalístico e da cultura profissional. ${ }^{6}$

Em relação aos estudos brasileiros, o referencial teórico é similar, mas o modo de aplicação é distinto, uma vez que a revisão bibliográfica é apresentada de forma mais sucinta. Como - na maioria dos casos - esses trabalhos são publicados no formato de capítulo de livro ou paper (ao contrário das pesquisas portuguesas, que são publicadas como livros autônomos), o espaço é reduzido. Outra peculiaridade, no caso brasileiro, é que, na maior parte dos trabalhos acadêmicos, as referências teóricas são inseridas ao longo do corpo da análise, ao contrário das obras portuguesas, que seguem o padrão de apresentação preliminar das questões conceituais antes da análise dos dados. Entretanto, as bases conceituais e bibliográficas seguem o mesmo enquadramento analítico, nos termos já

das Ciências Sociais, os mais citados são: Michel Foucault, Pierre Bourdieu, Anthony Giddens, Todd Gitlin, Erving Goffman e Jürgen Habermas. (4) No campo específico da Sociologia do Ambiente, sobressaem-se os seguintes autores: Pascal Acot, Frederick Buttel, Edgar Morin, Michel Serres, Riley E. Dunlap, Catton William.

${ }^{5}$ A sistematização teórica feita por Pereira Rosa encontra-se no primeiro capítulo de seu livro A Quercus nas notícias (2006).

${ }^{6}$ Como se trata de teorias amplamente conhecidas no meio acadêmico, tanto no Brasil como em Portugal, consideramos desnecessário o detalhamento delas aqui, visto que leitores dos dois países têm acesso à bibliografia original mencionada. Para exposições detalhadas sobre esses temas, consultar também: Traquina, 1993; Traquina, 2001; Sousa, 1994; Sousa, 2003; Sousa, 2004; Wolf, 1995. 
detalhados acima. Em alguns casos, até as referências bibliográficas dos estudos são as mesmas, especialmente em relação às teorias do jornalismo.

Outra convergência entre os estudos analisados é o respaldo das ciências sociais, especialmente a sociologia e a ciência política. A sociologia do ambiente e a ecologia política são duas das principais referências básicas. Do ponto de vista da forma de análise, os estudos portugueses conseguem combinar extensa e detalhada análise empírica com o exame de questões teóricas de relevo. As pesquisas brasileiras, por sua vez, apresentam escopo teórico e analítico centrado em questões mais específicas, como a análise de campanhas oficiais para combater o fogo na Amazônia (Costa, 2006), a cobertura de imprensa sobre questões indígenas (Matos, 2001), a relação entre empresariado e ambientalismo (Ungaretti, 1998), a cobertura jornalística sobre alimentos geneticamente modificados (Mota et alli, 2006), além de uma gama de análises sobre a cobertura jornalística da Rio 92.

\section{Aspectos específicos}

No rol dos aspectos dotados de maior especificidade foram incluídos aqueles que se voltam diretamente para as rotinas produtivas e as questões profissionais, tais como as características dos relatos jornalísticos sobre ambiente, o grau de complexidade técnica dos assuntos noticiados, a formação dos jornalistas e o processo que levou as temáticas ambientais a se estabelecerem na agenda da mídia.

Quais as características que marcam os relatos jornalísticos sobre ambiente?

A questão é analisada por Ricardo Garcia (2004). O autor parte da premissa de que o fazer jornalístico sobre ambiente já se tornou dotado de determinadas especificidades, apesar de manter outros elementos característicos das práticas, rotinas e procedimentos do jornalismo convencional. Conforme o autor do livro "Sobre a Terra: um guia para quem escreve e lê sobre ambiente", a trajetória do jornalismo ambiental sofreu significativas redefinições nos últimos anos. Se na década de 1970, por exemplo, a notícia ambiental se enquadrava em reduzidas e simplificadas categorias, como acidentes, anúncios de medidas governamentais e curiosidades científicas, com o passar do tempo, novos enquadramentos foram surgindo. 
Uma hipótese que apresentamos a respeito dessa redefinição, a partir da leitura das observações de Ricardo Garcia, é a de que as especificidades foram sendo gestadas a partir de uma convergência de diversos atores, processos, fatores e estruturas. Em primeiro lugar cabe destacar a idéia de que a parca, mas gradual e crescente divulgação de notícias sobre o tema contribuiu para criar novos nichos de públicos, o que estimulou os meios de comunicação a investir na ampliação de equipes para a cobertura ambiental até então muito reduzida. Esse impulso levou à setorização e semi-especialização de jornalistas, provavelmente recrutados entre aqueles que já manifestavam interesse pela área ou atuavam como militantes ecológicos. Certamente esses não são os únicos fatores, mas podem ser apontados como alguns dos que interferiram na organização dos relatos jornalísticos sobre temas ambientais.

Em termos específicos, o autor identifica quatro elementos básicos que marcam os relatos jornalísticos sobre temas ambientais até o momento:

- A ênfase ao risco - contribui para dar força à matéria, devido ao teor dramático e apelo emocional. Afinal, quanto maior o potencial de risco, maior visibilidade e destaque ao fato, o que faz manter o tema na agenda dos media e nas instâncias de debate público.

- A duração indeterminada do processo - acentua o teor dramático, ao gerar suspense entre os receptores e despertar interesse para acompanhar o desenrolar dos fatos. Em muitos casos, o noticiário segue quase a estrutura dos enredos de teledramaturgia, com a divulgação das notícias em formato de sequiências ou episódios, com deixas de suspenses para os capítulos seguintes.

- A incerteza científica - como há diversidade de interpretações por parte dos especialistas com acesso aos media, esse elemento provoca debate, com opiniões divergentes, o que acentua o interesse da opinião pública e prolonga a permanência do tema na agenda pública.

- A complexidade técnica - esse fator pode ser desfavorável à cobertura, ao afastar o público leigo, além de representar um dos principais desafios para os jornalistas da área ambiental: como transmitir informações técnicas sobre áreas especializadas, como energia nuclear, eco-epidemias e outros que exigem conhecimento prévio do receptor? 
Essas características não são estanques e nem serão as únicas. Com o desenvolvimento das técnicas jornalísticas; a emergência de novas temáticas ou o desdobramento das já existentes; e o surgimento de outros nichos de públicos os relatos jornalísticos sobre temas ambientais passarão por novas alterações e outras características surgirão. Entretanto, até o estágio atual esse conjunto de observações é de extrema relevância para o aprofundamento do estudo acadêmico sobre as particularidades dos relatos jornalísticos sobre ambiente. Trata-se de uma contribuição significativa do autor, sem, contudo, fechar as possibilidades de análise.

Como os jornalistas lidam com a complexidade técnica de determinados temas ambientais?

Esse item constitui, na realidade, desdobramento da questão anterior, sobretudo da última característica dos relatos, apontada por Ricardo Garcia (2004). Apesar de considerar a complexidade técnica um elemento desfavorável à cobertura jornalística de temas ambientais, o autor avalia que a adequada utilização de fontes especializadas poderá superar o obstáculo da complexidade. Outra estratégia é o uso de metáforas, comparações e demais recursos explicativos acessíveis ao público leigo, de modo a simplificar a abordagem do tema, de forma sintética, mas sem simplificações e reducionismos.

Por outro lado, cabe destacar o papel didático do jornalismo no esclarecimento público e na instrução da população. Historicamente, o jornalismo exerceu papel expressivo na divulgação da agenda ambiental. Inicialmente, as questões ecológicas eram tratadas de forma episódica e fragmentada, mas com o passar o tempo, tornou-se um supertema, o que resultou numa especialidade do jornalismo (Barros, 2001). A função educativa dos meios de comunicação já foi ressaltada em vários estudos, inclusive em documentos da Unesco de ampla divulgação, a exemplo do célebre Relatório McBride, organizado pela Comissão Internacional Para o Estudo dos Problemas da Comunicação (1983). Na esteira dessa perspectiva, outros estudos foram realizados, com ênfase para o papel educativo e cultural dos media, como Sousa (2006). ${ }^{7}$

\footnotetext{
${ }^{7}$ O livro de Jorge Pedro Sousa Elementos de Teoria e Pesquisa da Comunicação e dos Media (2006) contém um capítulo denominado "Comunicação, sociedade, cultura e ciências da comunicação" (cap. I), o qual aborda o caráter cultural dos meios de comunicação. Da mesma forma, o livro de Rossana V. GAIA, Educomunicação \& Mídias (2001) apresenta ampla análise sobre o papel educativo dos meios de comunicação.
} 
Com base nesse pressuposto da função cultural e educativa dos media, Ricardo Garcia (2004) aborda a necessidade de maior investimento na produção jornalística sobre ambiente voltada para munir o cidadão de informações fidedignas sobre os temas explorados tanto pelos cientistas como pelas entidades não governamentais e as instituições públicas. Em sua avaliação, a notícia ambiental contextualizada, com informações corretas e com todas as explicações técnicas necessárias para a adequada compreensão pelo cidadão constitui um serviço de utilidade pública de grande relevância que os jornalistas e os media prestam à sociedade. Portanto, apesar de reconhecer as deficiências e lacunas existentes na produção jornalística atual, o autor reitera a necessidade de aperfeiçoamento na cobertura diária de notícias sobre ambiente de elevada complexidade técnica. Tal complexidade, em sua avaliação, não deve ser motivo para excluir o tema da agenda jornalística. Ao contrário, deveria servir de estímulo permanente aos jornalistas para a adequada compreensão das temáticas emergentes.

\section{O exercício de jornalismo ambiental exige formação específica?}

Esse debate também é desenvolvido por Ricardo Garcia em seu livro Sobre a Terra (2004). Para o autor, uma das principais dificuldades para a realização de uma cobertura ambiental de qualidade pelos meios de comunicação é a falta de conhecimento dos jornalistas sobre determinadas áreas do ambiente. Devido à carência de formação especializada, em sua avaliação, é difícil para os jornalistas sistematizarem informações oriundas de diversas áreas ou relacionadas com diferentes campos de conhecimento. Além disso, o autor adverte que poucos são os veículos que dão oportunidade aos profissionais para se dedicarem exclusivamente aos temas do ambiente. Em entrevista citada no artigo de Helena de Sousa Freitas (2007), Ricardo Garcia afirma que os jornalistas com boa formação e aptidão para cobrir ambiente oferecem uma contribuição social de alta relevância, pois podem decodificar os jargões das áreas especializadas e contextualizar os dados ou descobertas, contribuindo, assim, para democratizar o conhecimento ambiental e aumentar o nível de informação dos diversos públicos.

Acerca dessa discussão, Luísa Schmidt complementa, em entrevista citada por Freitas (2007, p.40): “O jornalista é um funcionário da Humanidade, tendo uma responsabilidade social e uma capacidade de influir na realidade fundamental na área do 
ambiente". O investigador Pedro Almeida Vieira, autor do livro Portugal: $O$ vermelho e o negro (2006), complementa que falta habilidade investigativa à maioria dos jornalistas que atuam na área ambiental. $O$ aprofundamento da apuração e a emergência de novas denúncias, em sua avaliação, ajudariam a fortalecer o jornalismo de ambiente e a aumentar sua credibilidade e repercussão pública.

Em suma, os autores que tratam dessa questão ressalvam que, apesar de o jornalista ser considerado um generalista, a falta de formação específica dificulta a cobertura de temas especializados e a própria relação com as fontes científicas. Amaral (1986) defende de forma enfática a formação específica como requisito para o jornalista compreender minimamente os temas sobre os quais escreve. Esse ponto de vista é compartilhado por Garcia (2004), que defende a idéia de que escrever sobre ambiente de forma simples e acessível requer habilidade e treinamento dos repórteres que atuam nessa área. Afinal, em sua avaliação, os temas ambientais não são mais esporádicos e a tendência é de ampliação e diversificação do elenco temático. Por outro lado, os investigadores admitem que há aspectos da cobertura de ambiente que não apresentam dificuldade alguma e podem ficar a cargo de jornalistas sem especialização, como as pautas corriqueiras e factuais. Entretanto, Garcia (2004) e Freitas (2007) reiteram que cada vez mais surgem assuntos complexos, que exigem maior conhecimento dos repórteres e editores de ambiente.

Como o ambientalismo rompeu as barreiras da descontinuidade na agenda dos media?

Apesar de perpassar praticamente todos os estudos, não há análises exaustivas e globais sobre as causas, fatores e atores que contribuíram para romper as barreiras da descontinuidade da agenda ambiental nos media. Entretanto, a partir de um exercício de metanálise, é possível tecer algumas inferências, com base na combinação de diferentes explicações encontradas nas obras analisadas. Em Portugal, Gonçalo Pereira Rosa (2006) põe em relevo a atuação de organizações não-governamentais e Ricardo Garcia (2004) destaca o papel dos próprios jornalistas. Luísa Schmidt, por sua vez, enfatiza o próprio papel dos media, sobretudo da televisão:

Os problemas ambientais - enquanto fatos reais, globais e complexos - alteram e constrangem o comportamento humano. Mas, ao serem 
mediatizados, ganham dimensões que não tinham antes. Essas novas dimensões passam a fazer parte da realidade do problema, pois integram o efeito retroativo e desdobrado da sua própria divulgação. $\mathrm{O}$ que leva a afirmar que eles são tanto problemas do foro biofísico como do foro do conhecimento público sobre eles. É isso que lhes dá a dimensão social da sua existência (p.20)

No Brasil, as análises são semelhantes, com ênfase ainda para o envolvimento de outros atores como a comunidade científica, com destaque para o pioneirismo da Sociedade Brasileira para o Progresso da Ciência (SBPC), tanto no plano científico como no político. (Fernandes, 1990). Enquanto a temática só passou a preocupar outras instituições científicas brasileiras após a Conferência de Estocolmo (1972), a SBPC desde 1965, já se ocupava com o debate ecológico, como registram Fernandes (1990) e Ferreira (1993). Algumas áreas isoladas das ciências já estavam efetivamente engajadas no estudo e na discussão dos temas ecológicos, tais como: Geografia, Geologia, Direito, Engenharia, Medicina Sanitária e Sociologia. A SBPC atuou como "catalisador desse movimento, produzindo significativos posicionamentos referidos à questão ambiental" (Viola, Leis, 1992, p.90).

O envolvimento do empresariado com os negócios ambientais é destacado por Ungaretti (1998) como outro fator que contribuiu para ampliar a cobertura dos media sobre a agenda verde, visto que começou a haver maior disposição das grandes empresas e corporações para financiar anúncios publicitários. Assim, infere-se que o somatório de todas essas forças contribuiu para ampliar a repercussão dos temas ambientais nos media tanto no Brasil como em Portugal, de acordo com as peculiaridades de cada país. Mais uma vez, portanto, pode-se recorrer aos pressupostos da teoria multifatorial da notícia (Sousa, 2006).

\section{Comentários finais}

As questões discutidas acima representam apenas um breve recorte do escopo das pesquisas realizadas. Tantas outras ainda poderiam ser incorporadas, caso o espaço permitisse. Contudo, é oportuno, a título de considerações finais, discorrer sobre aquelas que mais ênfase receberam nas pesquisas analisadas, inclusive para complementar as que foram contempladas anteriormente. Nessa perspectiva, destaca-se a relação entre 
jornalistas e cientistas do ambiente, a consolidação das organizações não-governamentais como fontes credíveis para os jornalistas e a relação entre a atividade de jornalista e a militância ambiental.

No Brasil, a primeira questão perpassa todos os estudos publicados na coletânea Meio Ambiente no Século XXI, organizado por Trigueiro (2005). O assunto também é discutido por Andrade (2004), Schmidt (2003) e Pereira Rosa (2003). Esses estudos destacam que, com a ampliação da divulgação de pesquisas científicas sobre temas ambientais, o interesse do público tende a crescer ainda mais. Um exemplo é a divulgação dos estudos sobre mudanças climáticas por meio de grandes reportagens, documentários e programas televisivos acerca dos métodos para a análise de geleiras e glaciares, desenvolvimento de técnicas para aferir o nível de emissão de gases poluentes e mudanças no regime de chuvas, entre outros.

Quanto à segunda questão, ou seja, a consolidação das organizações nãogovernamentais como fontes credíveis para os jornalistas, trata-se de um dos eixos do problema investigado por Gonçalo Pereira Rosa (2006), em seu livro sobre a consolidação da organização ambiental Quercus $^{8}$ como fonte de informação sobre ambiente em Portugal. Em sua visão, o crescimento da importância de movimentos cívicos "em representatividade e peso negocial nas sociedades contemporâneas modificou os relatos jornalísticos e promoveu a ascensão de fontes que a sociologia do jornalismo até então ignorara" (Pereira Rosa, 2006, p.8). A conclusão do autor é que tanto as ONGAS interferiram no modo de se fazer jornalismo sobre ambiente, como elas próprias também foram afetadas por essa intervenção, em decorrência das estratégias de aproximação dos jornalistas e adequação aos critérios de noticiabilidade e aos valoresnotícia.

A dificuldade inicial das entidades ambientalistas, conforme destaca o autor, estava em romper o estereótipo de movimentos de contestação, sempre dispostos a disparar críticas contra os governantes e gerar polêmica, na maioria das vezes, sem dados e informações de ordem objetiva. Assim, essas entidades eram procuradas pelos jornalistas apenas quando eles buscavam esse tipo de enquadramento. Essa relação esporádica e estigmatizada prejudicava os movimentos, pois sua imagem era associada

\footnotetext{
${ }^{8}$ Trata-se da principal organização ambiental portuguesa. O estudo se tornou referência para o estudo da inserção noticiosa das organizações não-governamentais em Portugal e na Comunidade dos Países de Língua Portuguesa.
} 
geralmente a casos específicos e suas declarações eram encaixadas em matérias já préformatadas, com o objetivo de acirrar os conflitos, numa perspectiva descontextualizada, que apontava, na maioria das vezes, para os comportamentos e fatos desviantes.

As entidades ambientalistas passaram então a investir em estrutura, recursos e estratégias para modificar a relação com os media e com os jornalistas e, assim, conseguirem intervir na imagem delas projetada para a opinião pública. (Pereira Rosa, 2006, p.39). Além disso, as entidades tentam manter-se em evidência, ao alimentarem notícias, gerarem controvérsias e demandas para que seus aliados e oponentes também se pronunciem sobre os temas discutidos. Outra estratégia é a polarização com as instituições governamentais. Enquanto os representantes do Governo tentam fixar suas ações, numa perspectiva positiva, as entidades não-governamentais ficam de plantão, prontas para apontar lacunas em todas as ações governamentais (Pereira Rosa, 2006).

O debate sobre a possibilidade de conciliar atividade de jornalista de ambiente e de eco-militante é um dos temas centrais dos estudos de Afonso Cautela ${ }^{9}$ (Freitas, 2007). Ele acrescenta que cada vez mais os veículos estão atrelados a grandes projetos editoriais, com acentuada dimensão comercial, que exigem profissionalismo e distanciamento dos jornalistas. Em sua avaliação, isso é entendido de ambos os lados (patrões e contratados) como a inexistência de vínculos militantes em relação a causas ideológicas e projetos sociais. Por outro lado, ele ressalva que o jornalista é um cidadão e, como tal, tem direito à livre expressão de suas idéias. A militância também é defendida por outros expoentes do ambientalismo português como Francisco Ferreira e Viriato Soromenho-Marques. O primeiro defende a combinação de "militância ecológica de bastidores ou de fundo" (nas escolas, por exemplo) com manifestações de grande porte para chamar a atenção da sociedade civil e do Estado. Já o segundo afirma em entrevista a Pereira Rosa (2006, p. 105) que "a ação dramática tem uma função essencialmente pedagógica. É uma metonímia, uma figura de estilo que visa concentrar o mundo num ponto para o qual se chama a atenção".

Por fim, cabe ressaltar que as pesquisas analisadas mostram o nível de reflexão e o conteúdo pertinente às linhas de pesquisa já consolidadas no campo da Comunicação

\footnotetext{
${ }^{9}$ Cautela foi um dos pioneiros na área de jornalismo e ambiente em Portugal. Ele próprio se autodefine como jornalista e como eco-militante. Apesar de defender a combinação das duas atividades, ele afirma que é difícil conciliá-las, devido à estrutura editorial dos jornais, que exigem isenção, imparcialidade e distanciamento.
} 
e do Jornalismo nos dois países, principalmente na pós-graduação. No primeiro caso, destacam-se abordagens sobre o papel dos media na formação de uma opinião pública voltada para a consciência ecológica e o desenvolvimento sustentável, além do papel educativo e da função cultural dos media. No segundo caso, o relevo está em pontos como formação técnica, relação com as fontes científicas, cobertura de temas especializados, interferências políticas e econômicas nos conteúdos noticiosos.

O primeiro nível (mais abrangente) mostra como é intensa a relação entre estudos de Comunicação/Jornalismo e o campo das Ciências Sociais nos dois países. O segundo, por sua vez, ressalta uma tendência presente também nos dois países de afirmação acadêmica do campo jornalístico, na tentativa de problematizar aspectos específicos da área, com abordagem mais independente em relação às Ciências Sociais. Entretanto, trata-se de uma tendência e não de uma dicotomia. Aliás, vários dos estudos examinados são fundamentados numa perspectiva relacional e integrativa, que combina elementos teóricos e enquadramentos específicos do campo da Comunicação/Jornalismo com suporte teórico-metodológico das Ciências Sociais.

\section{Referências bibliográficas}

AMARAL, L. O que é jornalismo científico. Revista de Comunicação Social. Fortaleza, v.16, n.1-2, p.59-69, jan./dez., 1986.

BARROS, A. T. de; SOUSA, J. P. Jornalismo e ambiente: análise de investigações realizadas no Brasil e em Portugal. Porto: Edições Universidade Fernando Pessoa, 2010.

BARROS, F. L. de. Ambientalismo, globalização e novos atores sociais. Sociedade e Estado. Brasília, v.21, n.1, p.121-137, jan./jun. 1996.

BOBBIO, N. A era dos direitos. Rio de Janeiro: Campos, 1992.

CLARKE, M. Formulating the problem. Oxford, 2001.

COMISSÃO INTERNACIONAL para o Estudo dos Problemas da Comunicação. Um mundo e muitas vozes: comunicação e informação na nossa época. Rio de Janeiro: Fundação Getúlio Vargas, 1983.

COSTA, L. M. Comunicação e meio ambiente: análise das campanhas de prevenção a incêndios florestais na Amazônia. Belém: Núcleo de Altos Estudos Amazônicos, 2006. 
DENCKER, A. F. \& KUNSCH, M. M. K. Comunicação e meio ambiente. São Paulo: Intercom, 1996.

FERNANDES, A. M. A Construção da Ciência no Brasil e a SBPC. Brasília: Editora da Universidade de Brasília, 1990.

FERREIRA, L. da C. Os fantasmas do vale: qualidade ambiental e cidadania. Campinas: Editora da Unicamp, 1993.

FIGUEIREDO, V. Globalização, meio ambiente e novos atores sociais. Sociedade e Estado, Brasília, v.21, n.1, jan./jun., p.119-120, 1996.

FREITAS, H. de S. Jornalismo de ambiente em Portugal: espécie em vias de extinção? Jornal dos Jornalistas, Lisboa, jan./mar, p.30-40, 2007. Disponível em: http://www.clubedejornalistas.pt/admin/Portal/LinkClick.aspx?tabid=925\&table=Links\&field=I temID\&id=529\&link=JJ29_Ambiente.pdf.

GARCIA, R. Sobre a Terra: Um guia para quem lê e escreve sobre o ambiente. Lisboa: Público, 2004.

HOBSBAWN, E. A era dos extremos. São Paulo: Companhia das Letras, 1995.

MOTTA, L. G. et al. (2006). Os transgênicos na grande imprensa: uma análise de conteúdo. In: NASCIMENTO, E. P. do; VIANNA, J. N. de S. Economia, meio ambiente e comunicação. Rio de Janeiro: Garamond, p.11-38.

OLIVEIRA, M.T.C. O jornalismo científico na abordagem das questões ambientais. São Paulo: Associação Brasileira de Jornalismo Científico, 1991.

PEREIRA ROSA, G. A Quercus nas notícias. Porto: Porto Editora, 2006.

SOUSA, J. P. As notícias e seus efeitos: as teorias do jornalismo e dos efeitos sociais dos medias jornalísticos. Coimbra: Minerva-Coimbra, 2000.

Elementos de teoria e pesquisa da comunicação e dos media. Porto: Edições Universidade Fernando Pessoa, 2006.

SCHERER-WARREN, I. ONGs na América Latina: trajetória e perfil. In: VIOLA, E. J. et al. Meio ambiente, desenvolvimento e cidadania: desafios para as ciências sociais. São Paulo: Cortez, 1995. p.161-180.

SCHMIDT, L. Sociologia do ambiente: genealogia de uma dupla emergência. Análise Social, Lisboa, v.34, n.150, p.175-210, out./dez, 1999.

TRIGUEIRO, A. Meio ambiente na idade mídia. In: TRIGUEIRO, André (Coord.). Meio ambiente no século XXI. Campinas: Autores Associados, 2005, p.75-90. 
VIEIRA, P. A. Portugal: O vermelho e o negro. Lisboa: Dom Quixote, 2006.

VIOLA, E. J. O movimento ambientalista no Brasil (1971-1991): da denúncia e conscientização pública para a institucionalização e o desenvolvimento sustentável. In: GOLDENBERG, M. (Org.). Ecologia, ciência e política. Rio de Janeiro: Revan, 1992.

WOLF, M. Teorias da comunicação. Lisboa: Presença, 1995. 